\title{
AN INVESTIGATION INTO THE HEALTH OF 1,530 PRE-SCHOOL CHILDREN
}

BY

\author{
PETER HENDERSON, M.D. (ABerdeEN), D.P.H., \\ Deputy Medical Officer of Health, Leyton, \\ Late Assistant Medical Officer of Health, St. Helens.
}

It is a recognized and unpleasant fact that approximately 16 per cent. of the entrants to the elementary schools of this country possess physical defects that require treatment ${ }^{1}$. Less clearly known are the age at which these defects first appear in the child's life and the factors giving rise to them. It was in an attempt to obtain this information that the investigation now to be described was made. During the period January-July, 1936 (inclusive), 1,530 pre-school children were examined at five Infant Welfare Centres in the Borough of St. Helens. It was found that, of the 1,014 children under two years of age, 526 (51 per cent.) had physical defects other than constipation and disorders due to faulty methods of feeding; and of the 516 children over the age of two years 362 (70 per cent.) had one or more bodily defects. The defects found, with the number in each age-group, are given in table 1. It is proposed here to deal only with the defects number 1-15 in this table as it is thought that the defects number 16-29, though certainly important, need no further comment.

\section{Digestive disorders}

(a) Due to faulty feeding. 104 infants were affected. 'Wind' and ' green stools' were most frequently complained of by the mother. More infants suffered from over-feeding and too frequent feeding than from underfeeding; and bottle-fed babies gave the most trouble. Careful investigation into the quality and quantity of the feeds and into the technique of feeding, with the utilization of ' test feeds' for breast-fed babies that failed to thrive, usually made it possible to set the infant on the right road within a reasonably short time. Only a few cases merited admission to hospital. True cases of summer diarrhoea were rarely seen. The practice of giving excess sugar to infants was found to be prevalent and hard to stop. In 192 cases this practice was admitted. It is interesting to note that of the 
TABLE 1.

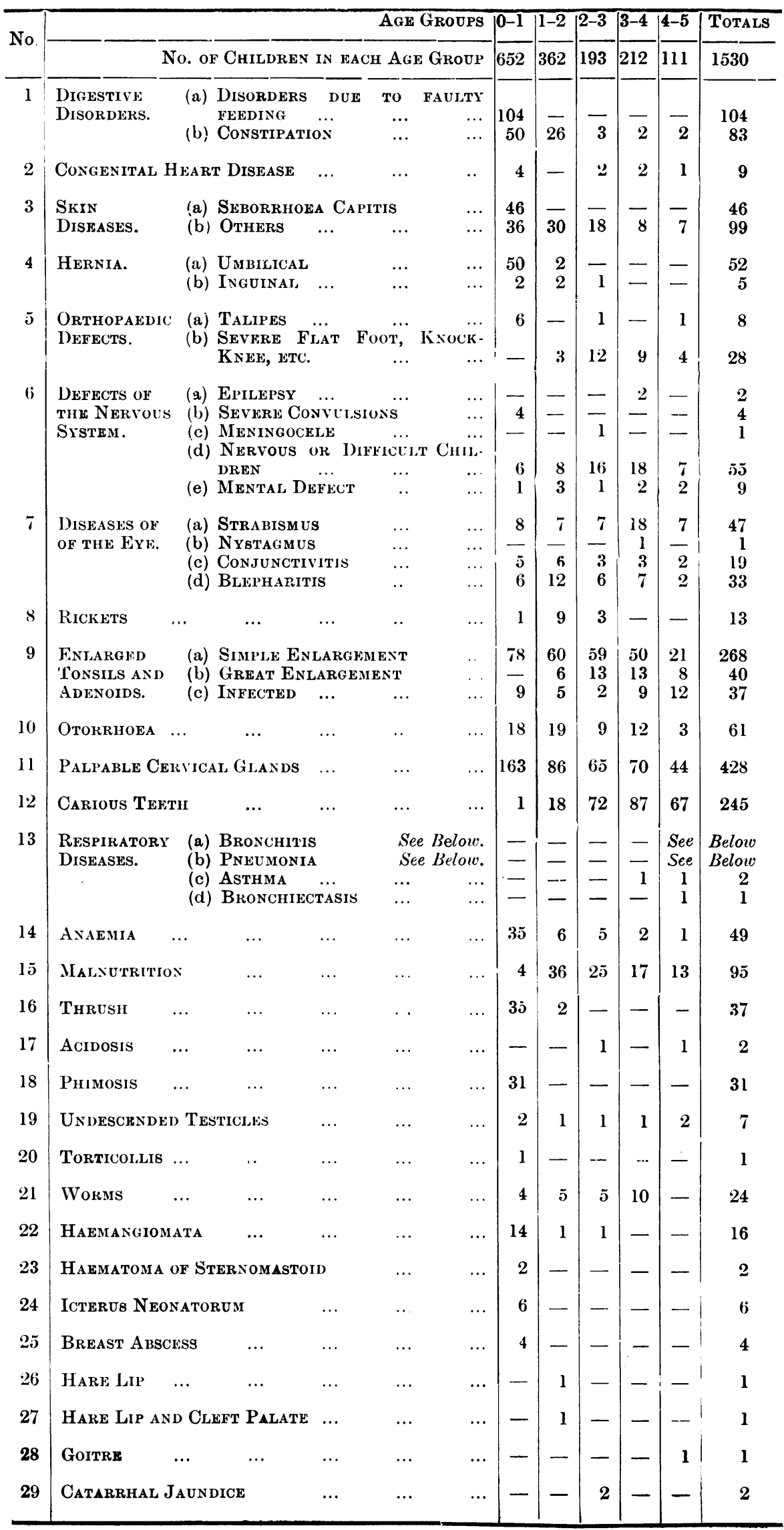


1,530 children, 623 were entirely breast-fed, 389 were breast-fed for at least two months or had breast feeds complemented by cow's milk (usually dried) for several months, and that 518 were fed entirely on cow's milk (usually dried).

(b) Constipation. This occurred in eighty-three known cases, and fifty of these were under the age of one year. It was usually associated with faulty feeding and its rectification rarely gave difficulty. A few cases were troublesome, and resort had to be made to drug treatment.

\section{Congenital heart disease}

Nine children had this defect: seven were cases of patent interventricular septum, one was a case of pulmonary stenosis and in the remaining case it was difficult to diagnose the lesion. No case of rheumatic heart disease was found; one child gave a history of ' rheumatism' but presented no sign of rheumatic infection.

\section{Skin diseases}

(a) Seborrhoea capitis. There were forty-six cases, all of which responded readily to treatment with liquid paraffin.

(b) Other skin conditions. Ninety-nine cases occurred. In the first two years of life lichen urticatus was the most frequent condition, while in the children over two years impetigo was the usual complaint. There were a few cases of infantile eczema.

\section{Hernia}

There were fifty-two cases of umbilical hernia and five cases of inguinal hernia. Of the fifty-two cases of umbilical hernia, fifty were found in the first few weeks of life and of these only two cases resisted treatment by strapping; two cases occurred in children aged 1-2 years and they are still under treatment. The five cases of inguinal hernia are to be treated surgically.

\section{Orthopaedic defects}

Thirty-six cases required treatment: eight were cases of talipes, and of these six received treatment in the first year of life. The remaining twenty-eight orthopaedic cases mostly comprised severe degrees of knockknee or flat feet. Unfortunately, minor orthopaedic defects were not noted.

\section{Defects of the nervous system}

Fifty-five children were found to be 'nervous' or ' difficult,' and in almost every case the mother was found to be over-anxious and unduly apprehensive about the child's health. Not one of these children merited treatment at a Child Guidance Clinic, and forty-one of the fifty-five were 
children over the age of two years; four infants had serious convulsions and two children, in the 3-4, year age group, suffered from epilepsy. There was one case of meningocele which was uncomplicated by talipes.

There were nine cases of grave mental defect: of these one was an idiot, four were imbeciles (two being mongols), and five were probably cases of low-grade feeble-mindedness. It was impossible to detect, in the time available, the number of high-grade feeble-minded children.

\section{Diseases of the eye}

Defects were found in a hundred children, and of these forty-seven had strabismus. There was one case of nystagmus, nineteen of conjunctivitis and thirty-three of blepharitis. The treatment of conjunctivitis gave little difficulty; but blepharitis cases, except those treated in the first year of life, tended to become chronic unless local treatment to the eyelids, the administration of malt and oil and free grants of milk were instituted as soon as the condition arose. Unless blepharitis is treated in early life it will, in all probability, haunt the youngster through many weary winters. Its prevention is easier than its treatment.

\section{Rickets}

It is unpleasant to have to note that thirteen cases of active rickets were found. Only one child showing rickets was under one year, and its home conditions were bad. Nine cases occurred in the age group 1-2 years, and three in the age group 2-3 years. The significant fact found was that in all twelve cases occurring in children over the age of one year attendance at the clinics was irregular and with a long interval between each attendance. Periodic examination of these children would have prevented the onset of rickets. Much more requires to be done in the 'following up' of absentees from Infant Welfare Clinics.

\section{Enlarged tonsils and adenoids}

Three hundred and forty-five children (22 per cent.) were found to be affected. In forty of these cases the tonsils were very large but were not obviously infected, and in thirty-seven cases definite inflammation or sepsis was present. The remaining 268 children had simple enlargement of tonsils only. The number of cases in this series is too small to permit any clear deduction being drawn. It can be noted, however, that the percentage of tonsils showing ' simple enlargement,' ' much enlargement' and ' infected' is higher in children over the age of two years than under this age. On the authority of $\mathrm{Gray}^{2}$, tonsils were considered to be enlarged if they projected ' beyond the plane of the glossopalatine arch.' The experience of the School Medical Service supports the view that a child with simple enlargement of his tonsils suffers no complaint that can fairly be ascribed to his tonsillar enlargement; but much more would probably be learnt if it 
were possible to follow a group of children from the pre-school years, having ' simple enlargement' of tonsils only, right through their school life. Sheldon ${ }^{3}$ cites infected tonsils as a possible cause of chronic bronchitis. In the case of one child, under the age of one year, who had its throat examined monthly, there suddenly developed a severe head cold that went on to bronchitis; after the attack the tonsils became enlarged. This raises the suggestion that perhaps a fair number of the cases of simple enlargement of tonsils follow such frequent infections as the common cold. The children with large or infected tonsils require frequent supervision as most, if not all, of them will require operation later, preferably before they enter school.

\section{Otorrhoea}

Sixty-one children had otorrhoea. It occurred in 3.6 per cent. of children under two years, and in $4 \cdot 6$ per cent. of children over two years. Oturrhoea was associated with enlarged or infected tonsils in five of the eighteen cases in the first year of life and with four of the nineteen cases in the second year of life. It is a striking fact that of the thirty-seven cases of otorrhoea under the age of two years only nine had enlarged or infected tonsils. It would be interesting to know how many of the remaining twentyeight cases ultimately showed signs of tonsillar infection. On the other hand, of the twenty-four children over the age of two years who had otcrrhoea, sixteen were associated with enlarged, or obviously septic, tonsils.

\section{Palpable cervical glands}

Still $^{4}$ has written ' $I$ would venture to question whether unusual palpability is necessarily a sign of disease . . . so that without any departure from health, they may be more palpable in one child than another.' In a series of 100 consecutive cases-Still does not give the ages - he found that 83 per cent. had palpable glands in the neck. Of the 1,530 children here reported on, 428 (28 per cent.) had palpable cervical glands: they were palpable in 24 per cent. of the children under two years of age and in 35 per cent. of the children over two years of age. In only twelve cases were the glands grossly enlarged; and of these four had developed abscess formation-one (in the 4-5 age group) was almost certainly tuberculous. In the case of the children under two years of age no septic area was found, from the history or from clinical examination, to account for the palpable glands; and only nineteen of the 1,014 children had carious teeth. As regards the children over two years of age, seventy-two had carious teeth. In this group it would be unwise to trust the absence of a history of any infective condition of the face or scalp as some of them had impetigo and sores and probably a good number had had these skin conditions though they denied a history of it. Even so, palpable cervical glands in children over the age of two years cannot be entirely explained by carious teeth or scalp and face sepsis. It is also true that slightly palpable cervical 
glands have no influence whatsoever on the health of the child. The information obtained from this series of cases fully bears out Still's statement.

\section{Carious teeth}

One child under the age of one year, 18 (4.9 per cent.) of the children age 1-2 years and 226 (43.7 per cent.) of the children over two years had dental caries. The following diagram illustrates clearly the swift rise in incidence of dental caries after the age of two years, and its steadily rising incidence up to the age of five years.

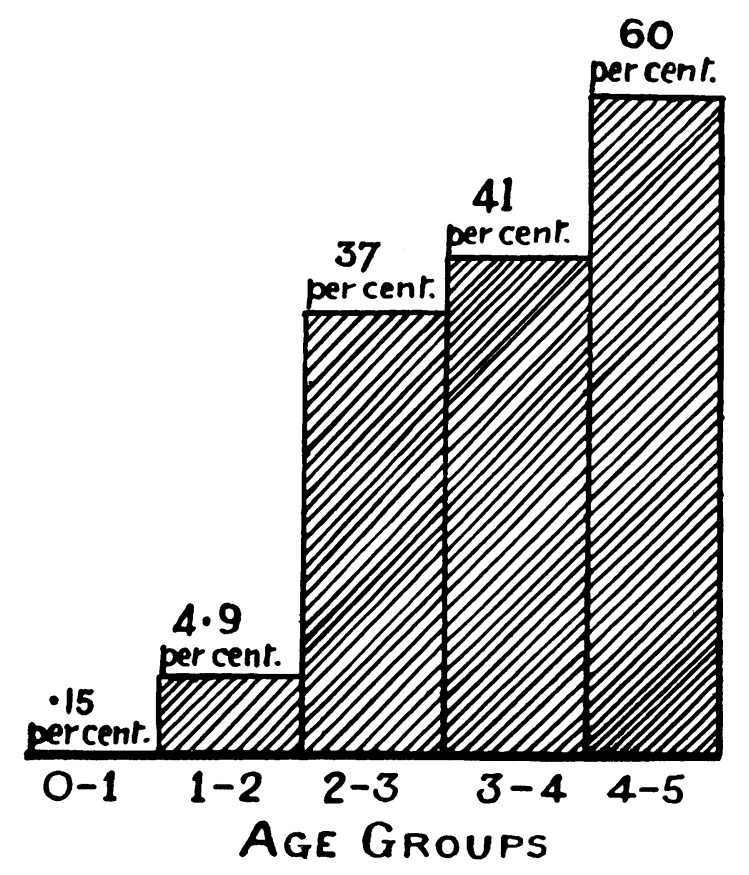

Fig. 1.

Of the 226 children over the age of two years having carious teeth, 111 were entirely breast-fed in infancy, twenty-four were fed partly on breast and partly on cow's milk, and ninety-one were fed entirely on cow's milk. In the case of the ninety-one children fed on cow's milk, their past record cards, unfortunately, did not make clear how many received cod-liver oil or other source of vitamin D, and the amount of vitamin $D$, as distinct from the amount of cod-liver oil, was not determined. As regards the breast-fed babes, on the evidence of Mellanby's work ${ }^{5}$, it might reasonably be assumed-apart from the great probability that the diet of these children and the absence of 
regular oral hygiene after the age of nine to twelve months more often than not would favour the development of caries-that the mothers' diet during pregnancy was inadequate, especially as regards the 'protective' foodstuffs. On the other hand, if an insufficient amount of vitamin $\mathbf{D}$ in the diet of bottle-fed infants and of pregnant and nursing mothers is the factor that plays a major part in the development of dental caries, it is then rather extraordinary why carious teeth do not occur more frequently in children aged one to two years. It is interesting, too, to note that half of the children with carious teeth were breast-fed. It is doubtful if this problem of the etiology of human dental caries is yet anywhere near complete solution. The results of this investigation into the incidence of dental caries merely emphasizes the information already obtained from school medical and dental inspections.

\section{Respiratory diseases}

Two hundred and fifty-five children (16.6 per cent.) either had bronchitis when they were examined at the Clinic or gave a history of one or more attacks. In 187 cases it was first contracted when the child was under the age of two years, and in sixty-eight cases when the child was over two years of age. Bronchitis was the most serious and troublesome condition encountered in this investigation. In St. Helens, it seemed to be regarded by the majority of mothers as an inevitable condition of childhood and one that merely called for a ' good bottle.' Its incidence was so high, and its effect on the child's development so deplorable, that it was thought worthwhile to investigate each case. It soon became apparent that 'teething,' measles and whooping cough-causes commonly cited in the text bookswere by no means the chief precursors of bronchitis. It was found that in 134 cases (52.5 per cent.) the first attack of bronchitis in the child closely followed either a catarrhal infection of the respiratory tract (colds, influenza, bronchitis) or some infective condition of the naso-pharynx (tonsillitis, sore throat) in one or more members of the family. This information was often given by the mother without direct questioning; in fact, it was the frequency of such unsolicited statements that prompted this line of enquiry in every case. In forty-seven cases (18 per cent.) the first attack of bronchitis complicated an attack of measles or whooping cough, and in only twentynine cases ( 11 per cent.) was the first attack associated solely with ' teething.' In forty-five cases (17.6 per cent.) no exciting cause could be found-' it just comes' as one mother put it. Perhaps the best explanation that can be offered to account for these forty-five cases (and perhaps, too for the twenty-nine cases associated with teething) is that given by Pearson and $W_{y} y_{l i e^{6}}$, . . a large number of cases of chronic bronchitis-from 
the evidence of the clinical history-are not primarily due to infection, but are an expression of inborn tendency to exudation: the allergic child.' In this series of cases, 'the large number of cases' was due to infection and only a minority may have been allergic. These results are set out in table 2 .

TABLE 2.

IMMEDIATE PRECURSORS OF FIRST ATTACK OF TOTALS. BRONCHITIS IN CHILDHOOD.

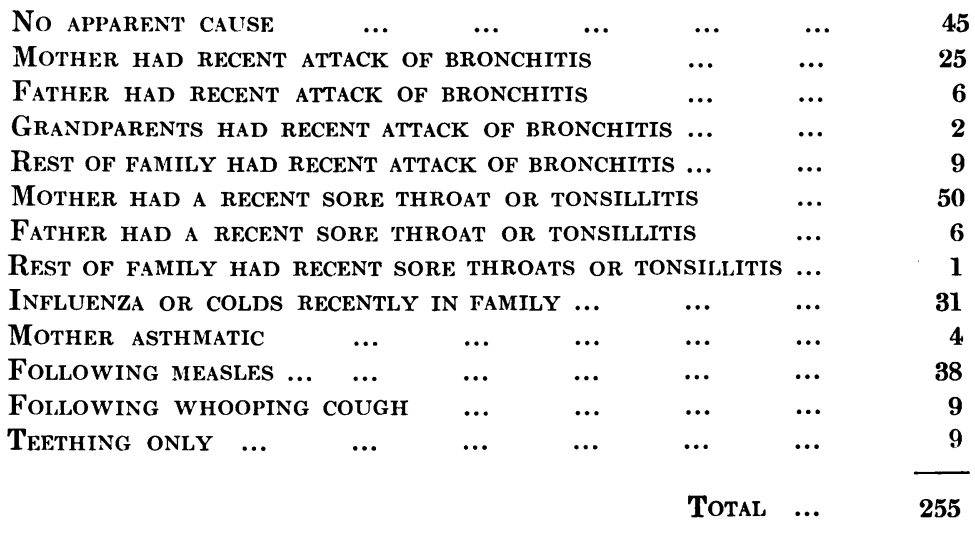

Bronchitis in the pre-school child is a serious and recurring disease, and its prevention is a matter of real importance. There is good reason to assume that it would become much less common if every young child could be properly isolated from any member of its family having an infective condition of his or her naso-pharynx or respiratory tract. Prevention is made more difficult on account of the frequency with which the mother is, herself, the potential source of infection. It is more common in over-crowded homes, but it does exist in good homes and where there is only one child in the family. That it occurs most frequently in the cold, damp, dark days of winter is probably due to the extreme sensitivity of the child's heat-regulating mechanism to atmospheric changes and also because it is the season of the year when adolescents and adults suffer most from infectious catarrhal conditions. Adequate feeding and good housing are indispensable; but, as far as the prevention of bronchitis is concerned, they are not enough. There must be further education of the parents.

Of the 1,530 children, 209 (13.6 per cent.) gave a history of measles and 70 (4.5 per cent.) gave a history of whooping cough. Eighty-nine children (5.8 per cent.) had one or more attacks of pneumonia; two suffered from asthma, and one from bronchiectasis. Though not respiratory diseases it is interesting to note that seventeen children ( $1 \cdot 1$ per cent.) had scarlet fever and seven ( 0.45 per cent.) had diphtheria; the high incidence of measles and whooping cough compared to the low incidence of diphtheria and scarlet fever in this series of cases is striking. In compiling these results the age of onset of measles, whooping cough and pneumonia was not noted when the children over two years of age were examined. It was found that 188 of the children over two years 
of age gave a history of either measles or whooping cough, and fifty-seven gave a history of pneumonia; but it was not determined if these diseases were contracted before or after the age of two years. This omission was only appreciated when these results were being analyzed. A further point that was not investigated was whether the incidence of bronchitis following measles and whooping cough was higher in those children who had a previous attack of bronchitis than in those who had no previous attack. No case diagnosed as pulmonary tuberculosis was found.

\section{Anaemia}

Forty-nine (3.2 per cent.) children were anaemic when examined. Of these, thirty-five (5.3 per cent. of children under one year) were children under one year. In view of Mackay' ${ }^{7}$ work, this is a surprisingly low figure. Here the examination was purely clinical; the figures would, probably, have been higher if more precise methods were used.

\section{Malnutrition}

Ninety-five children $(6 \cdot 2$ per cent.) were found to be undernourished. Of the 652 children under one year, only four (0.6 per cent.) were malnourished, whilst of the 878 children over one year ninety-one (10 per cent.) were undernourished. All the children who were not breast-fed received dried cow's milk at the Clinic for the first twelve months of life. The higher incidence of undernourishment in the later groups makes it clear that if dried milk were not supplied the number of children under one year showing signs of undernourishment would, undoubtedly, have been greater. These cases were well marked, all requiring extra nourishment. This evidence, together with the number of children showing dental caries and the fact that in eighty-two cases the nutrition of the mother was very poor, all suggested an enquiry into the social background of these children.

The social environment.-In 1,214 cases the full economic condition was known. The mother, at the Clinic, completed a form setting out the number of children in the family, their ages, the gross amount of the family's earnings and the amount of rent paid. The father had to sign another form giving the amount of his wages and/or other source of income for the previous four weeks. To prevent abuse, these figures were frequently checked by direct reference to employers. It soon became known that this procedure was being adopted and accurate wage returns were made. It was found that the father was employed in 772 cases and unemployed in 442 cases. Table 3 summarizes the findings :-

TABLE 3.

\begin{tabular}{|c|c|c|c|c|c|c|}
\hline \multirow[b]{2}{*}{ EMPLOYED } & \multicolumn{5}{|c|}{ DURATION OF UNEMPLOYMENT (442 PERSONS). } & \multirow[b]{2}{*}{$\tilde{n}+$ YEARS } \\
\hline & $\frac{1}{2}-1$ YEAR & $1-2$ YEARS & $2-3$ Y EARS & 3.4 YEAKS & 4-5 YEARS & \\
\hline \multirow[t]{2}{*}{772} & 38 & 78 & 64 & 72 & 66 & 124 \\
\hline & \multicolumn{5}{|c|}{ Totals } & 1,214 \\
\hline
\end{tabular}


In assessing the financial position of each family the man-value of each family was worked out; and for this purpose the man value caloric coefficients, set out in the Report on Nutrition ${ }^{8}$ by the Nutrition Committee of the British Medical Association, was adopted. Also, the minimum cost of food per man-value per week, estimated at 5s. 11d., by that Committee was here employed. In addition to food and shelter a family requires for the maintenance of health a sufficient amcunt of fuel, lighting, clothing, and cleaning materials. To cover these essentials different authorities have suggested different scales, but the scale set out in the 'Social Survey of Merseyside" 9 is a reasonable cne and it was used in this investigation. Table 4 gives this scale of needs.

TABLE 4.

Merseyside SURTeY.

\begin{tabular}{|c|c|c|c|}
\hline Man Value. & Fuer. & $\begin{array}{c}\text { Chothis, Cleansing, } \\
\text { Thent, etc. }\end{array}$ & Total. \\
\hline $1 \cdot 8$ & $2 \mathrm{~s} . \quad 5 \mathrm{~d}$. & 2 s. $8 d$. & 5s. $1 \mathrm{ll}$. \\
\hline $2 \cdot 2$ & 2 s. $5 \mathrm{~d}$. & 3s. $8 d$. & fis. 1d. \\
\hline $3 \cdot 4$ & 2s. $\quad b d$. & 5s. $8 d$. & 8s. ld. \\
\hline $4 \cdot 9$ & 2s. $5 \mathrm{~d}$. & 7s. $9 \mathrm{~d}$. & $10)=21$. \\
\hline
\end{tabular}

When these minima were applied to each family, after deducting the amount paid in rent from the total earnings, it was found that of the 1,214 families investigated 364 (30 per cent.) had incomes insufficient to cover the bare necessities of life. As rent, heating and lighting must be paid for, it was found that they were obtained at the expense of the amount that should have been paid for food. Table 5 gives this information.

TABLE 5 .

\begin{tabular}{|c|c|c|c|c|c|c|}
\hline \multirow{4}{*}{$\begin{array}{l}\text { Income Sufficinent } \\
\text { Income Insufficient }\end{array}$} & \multirow{4}{*}{$\begin{array}{l}\cdots \\
. .\end{array}$} & \multirow{4}{*}{$\begin{array}{l}\cdots \\
\cdots \\
x^{\prime}\end{array}$} & \multirow{3}{*}{$\begin{array}{l}\cdots \\
\cdots\end{array}$} & \multirow{2}{*}{$\begin{array}{c}\text { Employed } \\
669\end{array}$} & \multirow{2}{*}{$\frac{\text { UNEMPLOYED }}{181}$} & \multirow{2}{*}{$\begin{array}{c}\text { Totals } \\
850\end{array}$} \\
\hline & & & & & & \\
\hline & & & & 103 & 261 & $36 t$ \\
\hline & & & $\ldots$ & $77 \cdot 2$ & 442 & 1,214 \\
\hline
\end{tabular}

In 367 cases ( 30 per cent.) the amount paid in rent was less than 20 per cent. of the family income; in 667 cases ( 55 per cent.) the rent was between 20 per cent. and 30 per cent. of the family income, and in 180 cases (15 per cent.) it took more than 30 per cent. of the family income.

Incomes were found to be insufficient most frequently when the family was large. Table 6 gives the size of the families.

TABLE 6.

NUMBER OF CHILDREN IN FAMIIY.

\begin{tabular}{c|c|c|c|c|c|c|c|c|c|c}
\hline Total & 1 & 2 & 3 & 4 & 5 & 6 & 7 & S & 9 & 10 AND MORE \\
\hline 1,214 & 311 & 299 & 207 & 138 & 10 & 69 & 40 & 33 & 11 & 6 \\
\hline
\end{tabular}


In seventy cases (5.7 per cent.) the mother's management was scandalously poor, and no amount of propaganda would have had the slightest chance of permanently improving it. In at least thirty of these cases the presumption was that the mother was feeble-minded.

However regarded, the economic background of these children's lives is a sad one. Even in those cases in which the family income was deemed sufficient, the balance, after paying for essential needs, was often pitiably small. And in 364 families the income was insufficient to buy the minimum amount of food necessary for health. This problem of undernourishment is a vexed one and one difficult of solution. To-day it is, perhaps, the chief problem that preventive medicine has to face. 'The evidence that Malnutrition exists is conclusive . . . the physical condition of a large part of the human race is still far below the accepted standard and this inferiority is largely due to imperfect nutrition.' ${ }^{10}$ Too often is undernourishment ascribed to bad management on the part of mothers; the adoption of this view merely clouds the issue, though it provides an easy excuse for ignoring the larger problem. As far as this investigation was concerned, it was found that bad management played but a minor part, thus confirming the opinion of the Nutrition Committee of the British Medical Association ${ }^{8}$.

- . . the average housewife, with no expert knowledge of calories, proteins, etc., does, in fact, purchase by rule-of-thumb methods foodstuffs which broadly approximate to dietaries considered by physiologists to be satisfactory. The above statement is subject to her purchasing powers proving adequate to the needs of her family. When the amount of money available for the purchase of food is not enough to enable the housewife to buy what she needs (and without understanding the scientific reasons she usually wants the right things in approximately the right quantities) she must economize in certain directions. Experience has taught her that she must avoid complaints of hunger and of 'emptiness' from her family, so she buys a smaller proportion of expensive proteins and fats (such as butter) and a higher proportion of cheap carbohydrates-usually bread and, according to their seasonal price, potatoes.'

And the probability is that it is because the housewife buys so little first-class protein and 'protective' foodstufis that in this investigation it was found that only 47 per cent. of mothers were able wholly to breast feed their babes, that 44 per cent. of the children over two years of age had carious teeth, that 10 per cent. of the children over one year were undernourished and that 5 per cent. of the mothers showed very poor nutrition. Knowing that in the case of at least 364 families an adequate diet was unobtainable for financial reasons it is hard to explain why only ninety-five children and eighty-two mothers showed poor nutrition. If all the mothers had been carefully examined the total would, undoubtedly, have been higher, but the larger number would not have been anywhere near 354; either the dietetic opinion of the physiologists is wrong or clinical methods of investigation are imperfect. 


\section{Conclusions}

To state, without qualification, that 60 per cent. of the 1,530 children here examined had physical defects would be to give a grossly distorted picture of the health of the pre-school child. If it is agreed that (1) unusual palpability of neck glands is not necessarily and, in fact, rarely is, a sign of disease and (2) that simple enlargement of the tonsils has no adverse effect on the child's health (and until the contrary is proved this can be assumed to be the correct view) then only a minority of pre-school children will be found to have physical defects, other than carious teeth. But a substantial minority ( $16 \cdot 6$ per cent.) have had or still have attacks of k.ronchitis that in more than 50 per cent. of cases followed an infective condition of the naso-pharynx or respiratory tract of some other member of the family. Malnutrition was a problem of importance, but a problem of much greater importance was that 30 per cent of 1,214 families, whose economic state was specially investigated, had incomes insufficient in amount to buy the food stated by the Nutrition Committee of the British Medical Association to be the minimum essential for health. Carious teeth became a problem only after the age of two years, but then it became a serious one and cne that increased with age. Though only 2 per cent. of the cases had blepharitis this condition was difficult to cure and tended easily to recur. In 5 per cent. of the children the tonsils were greatly enlarged or infected and merited surgical treatment. Though cervical glands were palpable in 28 per cent. of the children, they cnly became a clinical problem in 0.78 per cent. of cases. Otorrhoea was present in 3.9 per cent. of the children, and 16 per cent. of the children under one year of age had to have their feeding investigated.

Though an increasing and more regular attendance at the Infant Welfare Centres will help to improve and foster the health-and thereby the happiness-of the pre-school child, it is yet felt that no great advance in the standard of health of the citizen of to-morrow can be expected until the problem of adequate feeding of all the children in the community is scientifically and thoroughly tackled.

\section{REFERENGES}

1. Newman, G., 'The Health of the School Child,' London, 1933.

2. Gray, 'Anatomy,' 18th Edition, London, 1057, 1913.

3. Sheldon, W. P. H., 'Preventive Aspects of Medicine,' London, 1934, 64.

4. Still, G. F., 'Common Disorders and Diseases of Children,' London, 1927, 526.

5. Mellanby, E., Med. Res. Council, Spec. Rep. Series, No. 191, 1934.

6. Pearson, W. J., \& Wyllie, W. G., 'Recent Advances in Diseases of Children,' 3rd Edition, London, 1935, 303.

7. Mackay, H., Med. Res. Council, Spec. Rep. Series, No. 157, 1931.

8. Report on Nutrition, Brit. Med. J., 1933, ii.

9. 'Social Survey of Merseyside,' Liverpool, I, 1934.

10. Interim Rep. of the Mixed Committee on the Problem of Nutrition, League of Nations, i, 1936. 